\title{
Modernity imperatives impact on the Russian coal industry enterprises institutional environment
}

\author{
Valeriy Bobrikov ${ }^{1 *}$, Nikita Ravochkin ${ }^{1,2}$, Elena Sedelnikova ${ }^{1}$, Rinat Gilyazov ${ }^{2}$, and Ammar Jamous ${ }^{3,4}$ \\ ${ }^{1}$ T.F. Gorbachev Kuzbass State Technical University, 650000, Vesennyaya str. 28, Kemerovo, \\ Russian Federation \\ ${ }^{2}$ Kuzbass state agricultural academy, 650056, Markovteva str. 5, Kemerovo, Russian Federation \\ ${ }^{3}$ Damascus University, Damasc, Syrian Arab Republic \\ ${ }^{4}$ National research Tomsk state university 634050, Lenina pr., 36, Tomsk, Russian Federation
}

\begin{abstract}
In recent years, there has been an increase in the influence of the imperatives of the modern world on the institutional environment of the national economy, which not only creates qualitatively new combinations of challenges, but also contributes to the emergence of multiple institutional gaps. The Russian coal industry is a representative example of an asymmetric institutional environment based on different technological paradigms. In the article, the authors analyze the inconsistencies of the institutional environment of the Russian coal industry with the requirements of the modern world and propose ways to overcome the revealed institutional gaps. The phenomenon of institutions is considered and their significance for the economic sphere is determined. The main institutions of the market economy are presented. The influence of the imperatives of our time on the institutional breaks of the coal industry is indicated. The importance of improving the quality of the institutional environment has been substantiated. The state of the institutional environment of the Russian coal industry is critically analyzed. The directions of corrections of the identified problem areas are proposed for the purpose of innovative development of the domestic coal industry. The mutual influence of formal and informal institutions was clarified. The importance of the innovative development of the Russian coal industry in conjunction with investments in human capital is determined. Finally, the main results of the study are summarized.
\end{abstract}

\section{Introduction}

From the standpoint of the systemic and functional approaches, the coal industry in the heterogeneous structure of the Russian economy will be designated as a component of the fuel and energy complex and can be labeled as "basic". Mainly, such an understanding comes through the aspects of ensuring the progressive and evolutionary development of the entire national economy that are significant for the country. However, the main and still unresolved

* Corresponding author: bvn@kuzstu.ru 
problem of the coal industry is institutional. According to the authors, this is due to the underestimation of the role of the institutions themselves. This leads to the appearance of corresponding gaps, primarily related to innovation. At the same time, it should be noted that at the federal level, the production and development of innovations are articulated as a priority area of development.

Modern coal production is a complex socio-technical system. The most important role of institutions is to coordinate the norms of interaction between participants, which would increase the predictability of their actions. Lagging behind in innovation only aggravates institutional contradictions in the realities of nonlinear world dynamics. The key requirement for modernizing the economy and overcoming the lag behind developed countries correlates with the ability of institutions to transform available resources into real development programs.

Like any other industry, the coal industry cannot evade the imperatives of modern society as the leading trends in world development. Of great importance among these imperatives are innovative technologies, the ignoring of which causes a crisis in economic sectors and leads not only to dysfunctional institutions, but also to deinstitutionalization in general. A significant place today is given to technologies that create, in aggregate, a certain "way" reflecting the general level of scientific discoveries and innovative development of the country, as well as setting a panorama of possible options for further modernizing the economy $[1 ; 2]$. Thus, the purpose of this work is to analyze the inconsistencies of Russian institutions in the coal industry with the requirements of the modern world and to propose appropriate ways to overcome institutional gaps.

\section{Theory}

It is customary to understand institutions as the most common culturally determined ways of thinking and interacting with regard to groups of relations and interests that are significant for each particular society. The functionality assigned to a specific institution is strictly defined. It is also significant that the effectiveness of the functioning of institutions is associated with the optimal use of the resource. Note that, being permeated with multiple connections, institutions not only indirectly relate to and to some extent cover the entire society, but also represent open systems that are not isolated from each other. As social life became more complex, institutions acquired two most important characteristics complementarity and heterogeneity, which determine their potential to formulate responses adequate to their time to challenges that are qualitatively different for their time against the background of actualizing new needs [3]. Based on the foregoing, the authors emphasize that the processes of institutionalization of social interactions in a particular area acquire extreme significance in the context of the pragmatics of the evolutionary variant of development.

Research interest in institutions is explained by the fact that they allow us to understand real-life conditions and identify ways of further development, which has acquired particular relevance in connection with the pragmatic turn that has taken place in science. In the most general form, the economic institutions of a particular industry are a refraction of the motives of behavior adopted in the country and the socially approved and encouraged activity of market participants in the realities of the adopted system of formal norms. In addition, the use of certain criteria and parameters allows us to see how specific institutions affect the result of the activities of economic entities. In terms of their functions in the economy, institutions are an alternative to competition, which is still considered by many as the only tool for ensuring progress and achieving entrepreneurial success. The authors believe that the defining institutions for a market economy are (1) the level of development of the legal system, (2) features of the development of culture, (3) the norms and customs of business 
etiquette, (4) the system of public administration, (5) the state of infrastructure, (6) mass media, (7) education and science.

The interconnected set of formal and informal institutions of a particular industry creates an institutional environment that outlines the framework of what is permissible and allows for the use of sanctions for significant deviations from the current "rules of the game". Taking into account the essential characteristics of institutions, we believe that habits in correlation with the level of trust become the catalyst for the specifics of the interactions carried out within the framework of a specific institutional environment. It follows that institutions are becoming an important addition that repairs the asymmetry of an imperfect market, the actions of whose participants, moreover, given their limited number, are focused on only competition and are not focused on improving the currently dominant system of relationships.

The imperatives of the modern world have led to multiple crises that have been observed in recent decades in the field of international and national economic relations. Institutional gaps were revealed almost everywhere, which indicated significant negative deviations from the norm of performance and management practices from goal-setting, planning and the hierarchy of interests of top management. Any crisis phenomena will reformat ideas about what is important and priority, creating the need for remodeling existing institutions. Such bifurcation points consolidate the efforts of theorists (the scientific community) and practitioners (numerous participants in economic relations) to solve two important problems: finding points of future growth and correcting low institutional efficiency [4].

Depending on the scale of the problem that has arisen, improving the quality of the institutional environment can be carried out at the level of the national economy or a separate industry. In both cases, the dialogue between scientists and representatives of government and business is the joint implementation of advanced research and development. At the same time, in the realities of Russian geography and the location of industrial enterprises, the factor of subjectivity and the creation of individually determined effective solutions are growing as never before. Accordingly, in the domestic business, when implementing the transformations of the institutional environment, additional difficulties are inevitable associated with the search for optimal configurations of relationships and interactions and the creation and maintenance of comfortable conditions for the functioning of the industry business. By and large, the main reason for the lag of any sectoral institutional environment is the ignorance of innovations "against the background of the deployment of progressive structural changes in the world economy" [5]. The national coal industry is no exception to the vicious circle of confirmation of an unformed effective system of institutions that would provide adequate answers to the emerging challenges of the time. By and large, Russia can only compete in a small number of sectors of the national economy.

The unique and rapid transition of the coal industry from an administrative-command to a market economy has not yet been called successful. This is due to the fact that the hastily carried out modernization of the regional institutional environments of the coal industry simply did not provide a reduction in the volume of transaction costs. Overcoming the inertia of the ineffective development of the institutional environment of the Russian coal industry requires diagnosing problem areas and formulating proposals to overcome them. The results of this theoretical search can be used in the applied application of the methodology aimed at correcting the gaps in the formation of an innovative institutional environment.

\section{Results and discussion}

The Russian coal industry is a fairly representative example for analytics. So, on the one hand, it managed to enter the rails of a market economy, but at the same time it managed to preserve a unique competitive institutional environment, which is a "mix" of the Soviet, transitional and modern periods of development. The architecture of the coal industry clearly 
indicates that the updated institutional environment is extremely asymmetric, since the greatest burden on a number of predominantly informal institutions of the transition period does not produce the desired effect. At the same time, some effective institutions of our time are not fully involved, and the structures of the Soviet type are rudiments and, logically, should have been retired altogether due to belonging to the technological structures of the lower level, but in spite of everything they are still present in the institutional environment. We believe that such an institutional environment, which has developed today thanks to the actions of participants in the domestic coal industry, does not at all favor the conduct of entrepreneurial activity in the logic of a market economy based on neoclassical principles [6$8]$.

Comparative analysis with the world's leading countries for various branches of entrepreneurial activity shows that in the absolute majority of ratings, Russia lags far behind those countries where innovation has led to economic growth. By and large, this "normal" institutional environment for the majority of participants in the domestic coal industry is nothing more than a delay in the implementation of the necessary transformations. However, in the long term, such delays, one way or another, will reduce the competitiveness of the industry on a global scale, lead to a decrease in government support and further degradation of the resource potential of coal-mining regions, exacerbate the existing price disparity, weaken stable ties and conditions for business and production processes, etc. Since any transformations carry comparative advantages, the task of modernizing institutions, and even taking into account the deep processes taking place in the global coal industry, becomes urgent.

It is known that institutions acquire their meaning and successfully implement their functionality depending on the "address" of their establishment. The domestic coal industry has a rich geography, covering a wide variety of regions. Hence, it follows that the starting point for correcting institutional gaps is the maximum involvement of coal market players in institutional transformations, since the insignificant coverage of participants simply will not allow fixing this problem area.

Making adjustments to the institutional environment of the coal industry presupposes changes in the conditions for doing business. The first point that needs to be taken into account is the introduction of up-to-date formal rules that would greatly simplify the conduct of business in the coal industry. This is necessary, since the alignment of the institutional environment is impossible without norms and mechanisms of interaction between the participants established from above, rooted in the state legal system. In the context of openness of information, formal control increases transparency in terms of the resources used for transactions by each of the participants. An analysis of Russian realities reveals the obvious: for a fair leveling of the institutional environment, rules, including those of regional and local significance, are required.

It is expected that the official consolidation of provisions that are congruent with modern axiological expectations, coupled with the immediate application of sanctions for violation of the norms and rules of economic behavior, will help overcome the imbalance in the institutional environment associated with the priority of informal institutions. These regulations are complementary to the basic institutions of the coal industry and often leave a noticeable imprint on the thinking of the participants, which results in deviant behavior. Only a powerful undermining of trust in these institutions, presented in the text of normative acts and implemented in practice, will make it possible to question their legitimacy. In turn, informal interactions carried out within the framework of the Russian coal business were approved by economic agents. Business entities, although they take into account possible collisions with formal institutions, but the high assessment of informal structures is explained by them as a guaranteed alternative option for the execution of transactions, including at an inflated cost. In our opinion, the continuing nature of the presence in the coal industry of 
corruption, compensation, as well as appeals to the tax authorities, prosecutors, local authorities and the unfair use of insider information in building competition strategies by enterprises not only infringes on the rights of other participants and reduces the possibility of reinvesting profits in the modernization of infrastructure, but it also strengthens the rentoriented trajectory of the industry's development. Thus, even in spite of the general decline in the quality of the institutional environment, the influence of informal institutions will grow unless the already mentioned necessary changes are made to the legislation, which has become irrelevant to modern realities.

The next direction, the development of which will inevitably ascending provided implementation transformation of formal and informal institutions is improving the quality of human capital. Analysis of Russian realities shows clear negative trends of stagnation and degradation of human resources, which creates the main difficulty - a weak perception of the industry for innovation, in connection with which the evolution of the institutional environment of the coal industry is being implemented with a significant lag in comparison with other coal-mining countries [9]. Numerous interesting facts that run counter to international practice, which show a significant lag in innovation activity on the domestic private enterprises in their comparison of foreign private companies. As a result, the crisis in the aspect of the production of advanced creative ideas contributed to a reduction in inventions, the implementation of applied developments, a decrease in the share of the fifth and sixth technological paradigms in the structure of the national economy. The main negative consequences of technological backwardness of the coal industry are difficult design of the institutional environment and, consequently, the loss of its investment attractiveness.

It follows that in order to align its institutional profile of the coal industry, it is necessary to propose and implement epoch-making innovations, which are simply impossible without the formation of an adequate attitude and readiness of management to invest a significant amount of private investment resources in the development of knowledge transfer mechanisms [10-12]. Urgent investment in the human capital of the coal industry is in tune with the imperatives of the post-industrial era, where the primacy of education, science, rationality and technology is a vital element of a high-quality and efficiently functioning institutional environment. The development of fundamentally new ideas, competitive and oriented towards revolutionary production changes, will reset the current sluggish nature of the technological renewal of the industry and, in general, will have a positive effect on the brand and the technological image of the Russian coal industry. Finally, one of the future qualimetric markers that will allow us to evaluate the institutional transformations we have proposed is an independent expert diagnostics of the industry's transition from raw materials to processing, and then to innovative with a real practical result of activity.

\section{Conclusion}

Of course, coal industry institutional environment transformation could be supplemented by proposals for a broader coverage of the structural elements that influence it. Revealing the problems and proposing changes in the directions of "power", "culture", "family", although it is of some interest for institutionalist researchers, but, in our opinion, today the implementation of any transformations simply will not give such a strong effect for evolutionary development coal industry.

It is safe to say that modern society will continue to multiply its imperatives, which will require systematic and urgent institutional changes in the coal industry. The analysis of the problem points of the development of the institutional environment of the coal industry, carried out by the authors, revealed its asymmetry.

As the post-Soviet practice has shown, Russia cannot successfully import advanced Western institutions into its own contextual realities. The formulated directions for the 
implementation of institutional transformations are focused on growing their own institutions. Of course, our proposals require a significant investment of resources, but their implementation will allow us to form regional growth points, level the profile of the environment and, most importantly, replace weak and quasi-market institutions, thereby contributing to an increase in the efficiency of coal industry management. An integral assessment of the results is proposed to be carried out in the logic of institutionalism, that is, when referring to the analysis of transaction costs.

\section{References}

1. L. Gokhberg I. Kuzminov, E. Khabirova, T.Thurner, Futures, 115 (2020)

2. A. Mouzakitis, Frontiers of Sociology, 2 (2017)

3. A. Moravcsik, Journal of Common Market Studies, 56 (2018)

4. I. Jonek-Kowalska, Resources Policy, 55 (2018)

5. M.A. Gasanov, A.P. Tyutyushev, Sib. J. of Science. 1, 166 (2012)

6. S.I.Arbuzov, A.V.Volostnov, V.S.Mashen'kin, A.M.Mezhibor, Russian Geology and Geophysics, 55 (2014)

7. I.I. Dorband, M. Jakob, J.C. Steckel Energy Policy, 147 (2020)

8. A. Libman, Europe-Asia Studies, 59 (2007)

9. M. Kopacz, D. Kryzia, K. Kryzia, Journal of Cleaner Production, 159 (2017)

10. D. Chattopadhyay, M.D. Bazilian, B. Handle, C. Govindarajalu The Electricity J., 34 (2021)

11. R.B.Finkelman, A. Wolfe, M.S.Hendryx, Energy Geoscience, 2 (2021)

12. R. Nureev, V. Volchik,W. Strielkowski, Social Science, 9 (2020) 